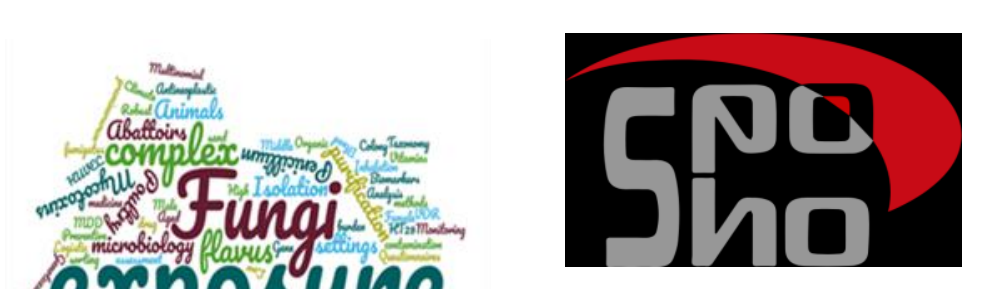

\title{
Is the quantitative cut-off a suitable surrogate to ensure a good indoor air quality regarding the mycobiota in health care facilities?
}

\author{
C. Viegas ${ }^{1,2}$, B. Almeida ${ }^{1}$ \\ 1 H\&TRC- Health \& Technology Research Center, ESTeSL- Escola Superior de Tecnologia da Saúde, Instituto \\ Politécnico de Lisboa. \\ 2 Centro de Investigação e Estudos em Saúde Pública, Escola Nacional de Saúde Pública, ENSP, Universidade \\ Nova de Lisboa, Lisbon, Portugal
}




\section{Background}

Studies have reported that there is a significant relationship between hospital infections and bioaerosols.

Fungi are present in clinical indoor environments and play important roles in human diseases in patients and staff.

(Lal et al. 2017)

Aspergillus is a common fungus in invasive infections, however, other fungi are enrolled as pathogens in immunosuppressed patients. 
The azole-resistant Aspergillus sp. has up to 30\% prevalence in some European hospitals, which report higher than $90 \%$ mortality rates.

(Van Paassen et al. 2016)

Control measures are crucial in clinical environments for reducing concentrations of airborne fungal contamination and to avoid invasive infections acquired from indoor air. 
We cannot fully eliminate fungi from indoor clinical environments and enforcement is needed to ensure, at least, proper Indoor Air Quality (IAQ) assessments.

Portuguese legislation established limit values for air bioburden in indoor environments in general, without any specific requirement for health care facilities. 


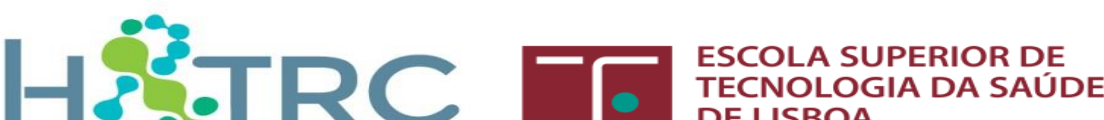 \\ DE LISBOA \\ 10 INSTITUTO

Table 1. Portuguese legal compliance for mycobiota according to Ordinance no. 359-A/2013.

\begin{tabular}{|c|c|}
\hline & Fungi \\
\hline $1^{\text {st }}$ requirement & - $\quad$ [indoor $]<$ outdoor] \\
\hline $\begin{array}{l}2^{\text {nd }} \text { requirement (to be applied when } \\
\text { the } 1^{\text {st }} \text { requirement is not fulfilled) }\end{array}$ & $\begin{array}{l}\text { - No visible fungal growth on } \\
\text { surfaces; } \\
\text { - Species should be evaluated } \\
\text { according Table } 2\end{array}$ \\
\hline
\end{tabular}

Table 1. Fungal conformity based on the species according to Ordinance no. 359-A/2013.

\begin{tabular}{|c|c|c|}
\hline \multicolumn{2}{|c|}{ Genera/Species } & Specific Condition of Conformity \\
\hline Common species & $\begin{array}{l}\text { Cladosporium } \mathrm{sp} . \\
\text { Penicillium } \mathrm{sp} . \\
\text { Aspergillus sp. } \\
\text { Alternaria } \mathrm{sp} . \\
\text { Eurotium spp } \\
\text { Paecilomyces } \mathrm{sp} . \\
\text { Wallemia } \mathrm{sp.}\end{array}$ & Mixture of species: $\leq 500$ CFU.m ${ }^{-3}$ \\
\hline $\begin{array}{l}\text { Non-common } \\
\text { species }\end{array}$ & $\begin{array}{l}\text { Acremonium sp. } \\
\text { Chrysonilia } \mathrm{sp} . \\
\text { Tricothecium sp. } \\
\text { Curvularia sp. } \\
\text { Nigrospora sp. }\end{array}$ & $\begin{array}{l}\text { One species: }<50 \text { CFU.m }{ }^{-3} \\
\text { Mixture of species: }<150 \text { CFU.m }{ }^{-3}\end{array}$ \\
\hline $\begin{array}{l}\text { Pathogenic } \\
\text { species }\end{array}$ & $\begin{array}{l}\text { Chryptococcus } \\
\text { neoformans } \\
\text { Histoplasma } \\
\text { capsulatum } \\
\text { Blastomyces } \\
\text { dermatitidis } \\
\text { Coccidioides immitis }\end{array}$ & Absence of any species \\
\hline Toxigenic species & $\begin{array}{l}\text { Stachybotrys } \\
\text { chartarum } \\
\text { Aspergillus versicolor } \\
\text { Aspergillus flavus } \\
\text { Aspergillus ochraceus } \\
\text { Aspergillus terreus } \\
\text { Aspergillus fumigatus } \\
\text { Fusarium moniliforme } \\
\text { Fusarium culmorum } \\
\text { Trichoderma viride }\end{array}$ & $\begin{array}{l}\text { One species: < } 12 \text { CFU.m }{ }^{-3} \text { (Several } \\
\text { colonies per plate) }\end{array}$ \\
\hline
\end{tabular}

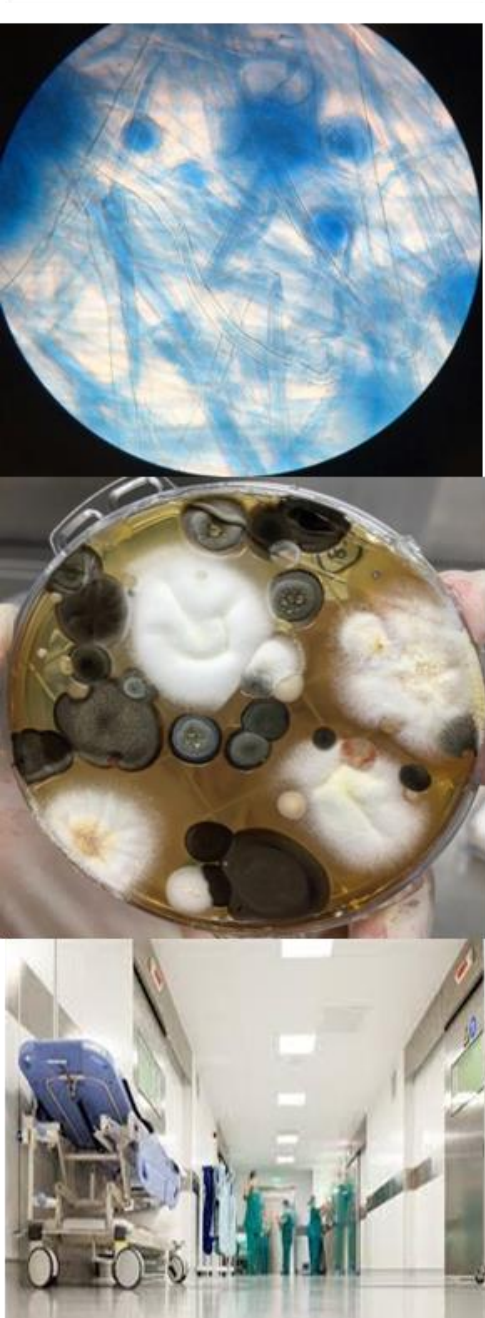


- This study focuses on the mycobiota assessment in 10 Primary Health Care Centers (PHCC) applying the IAQ Portuguese legislation as guidance.

- After the quantitative cut-off analyses $(\mathrm{I} / \mathrm{O})$ the fungal species identification was performed to verify if the fungal conformity was achieved even in those that comply with the I/O ratio. 


\section{Materials and methods}
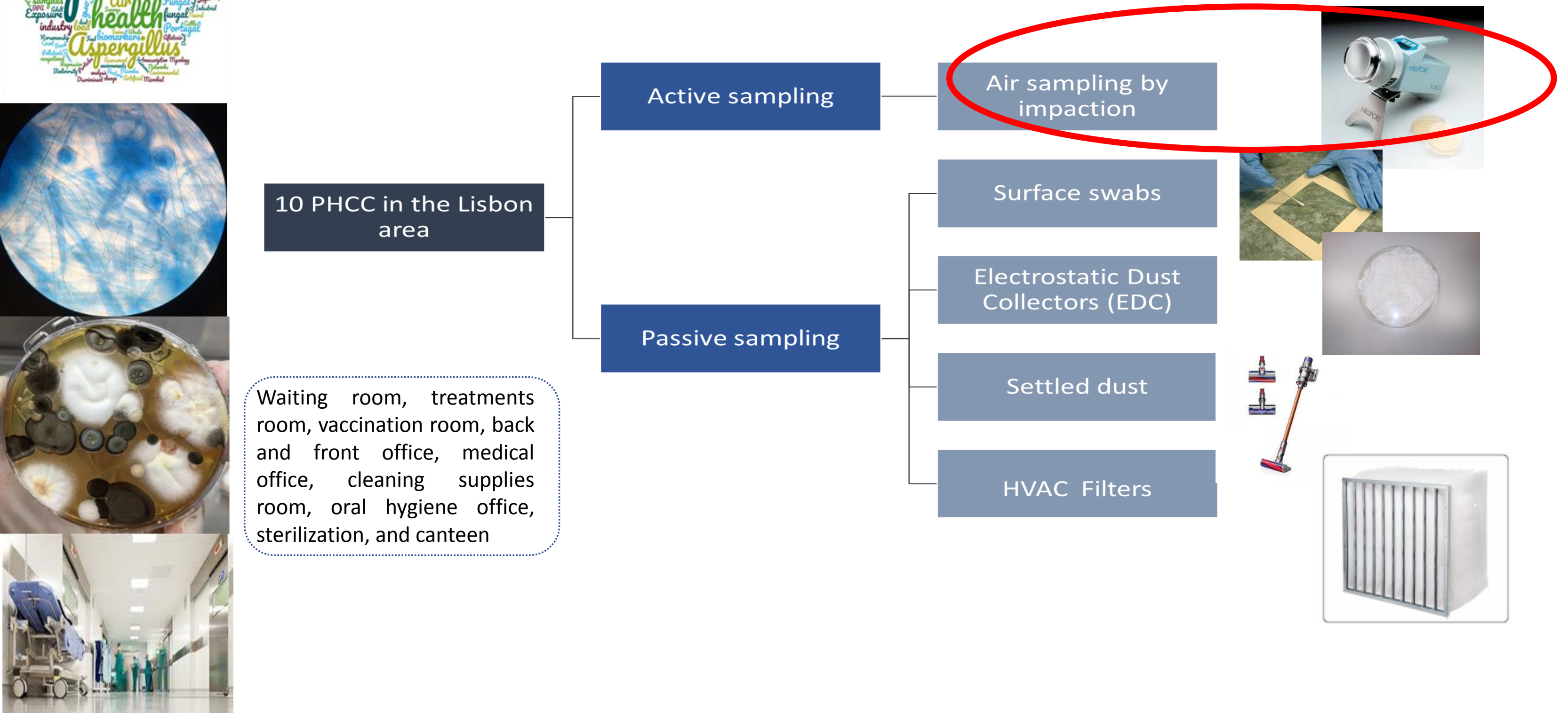

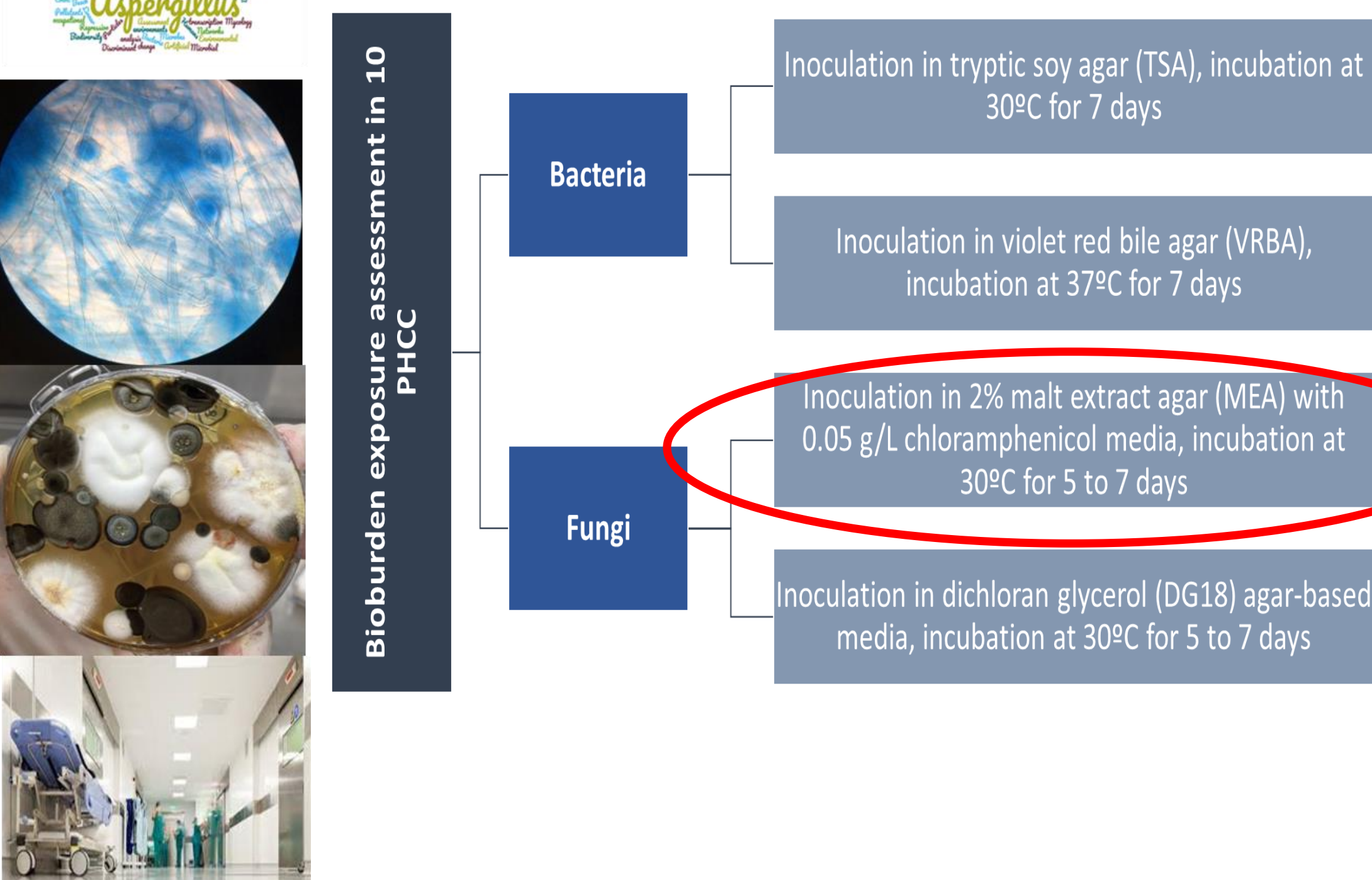

Bacteria
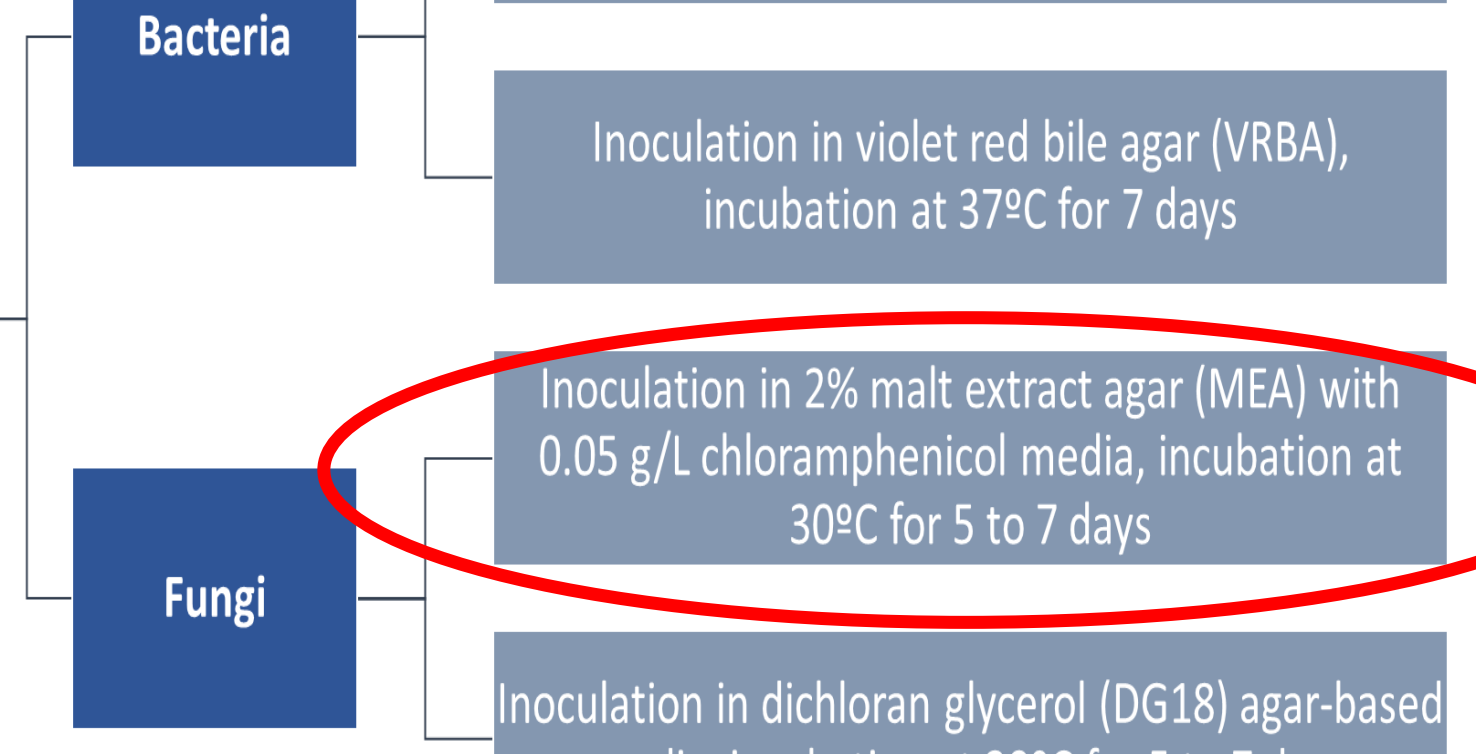

Inoculation in $2 \%$ malt extract agar (MEA) with $0.05 \mathrm{~g} / \mathrm{L}$ chloramphenicol media, incubation at $30^{\circ} \mathrm{C}$ for 5 to 7 days

Inoculation in dichloran glycerol (DG18) agar-based media, incubation at $30^{\circ} \mathrm{C}$ for 5 to 7 days
Other performed assessments in the same matrices:

- Fungal biomass

- Toxigenic fungal strains detection

- MRSA prevalence (all passive methods)

Azole resistance prevalence among the recovered mycobiota

- Mycotoxins

\section{Endotoxins}




\section{Results}

The median values on MEA ranged from $164 \mathrm{CFU} \cdot \mathrm{m}^{-3}$ (in the clean area of the sterilization room) to $508 \mathrm{CFU}^{-3}$ (in the treatments room). Among the 10 PHCC 60\% (6 out of 10) presented I/O $>1$.

\begin{tabular}{ccccc}
\hline PHCC & $\begin{array}{c}\text { Mean } \\
\left(\text { CFU.m }^{-3}\right)\end{array}$ & $\begin{array}{c}\text { Outdoor } \\
\left(\mathbf{C F U . m}^{-3}\right)\end{array}$ & $\mathbf{I / O}$ & Toxigenic species* \\
\hline $\mathbf{1}$ & 28.57 & 144 & 0.20 & \\
\hline $\mathbf{2}$ & 65 & 20 & $\mathbf{3 . 2 5}$ & $\begin{array}{c}\text { Aspergillus sections } \text { Circumdati } \\
\text { and Versicolores }\end{array}$ \\
\hline $\mathbf{3}$ & 479 & 612 & 0.78 & Aspergillus section Versicolores \\
\hline $\mathbf{4}$ & 402 & 260 & $\mathbf{1 . 5 5}$ & \\
\hline $\mathbf{5}$ & 291 & 96 & $\mathbf{3 . 0 3}$ & Aspergillus section Fumigati \\
\hline $\mathbf{6}$ & 155.5 & 228 & 0.68 & Aspergillus section Versicolores \\
\hline $\mathbf{7}$ & 474.91 & 140 & $\mathbf{3 . 3 9}$ & \\
\hline $\mathbf{8}$ & 526 & 384 & $\mathbf{1 . 3 7}$ & \\
\hline $\mathbf{9}$ & 505.71 & 508 & 1.00 & \\
\hline $\mathbf{1 0}$ & 520 & 208 & $\mathbf{2 . 5 0}$ & \\
\hline
\end{tabular}

- Aspergillus sections Versicolores, Circumdati and Fumigati were identified on air

- > 12 CFU. $\mathrm{m}^{-3}$

- Section Versicolores surpassed in PHCC 2, 3 and 6.

- Section Circumdati the load was surpassed in PHCC 2

- Section Fumigati in PHCC 5.

* Not complying with specific condition of conformity

- Sections Nigri, Aspergilli and Nidulantes were also observed. 


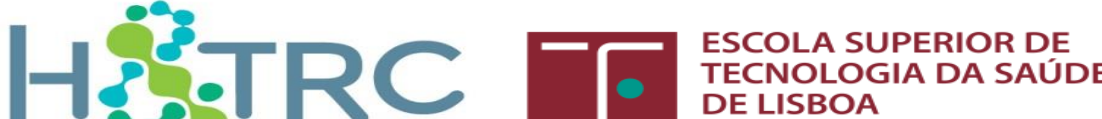

\section{Main findings discussion}

Mycobiota assessment should be always performed:

- to verify compliance with Portuguese legislation;

- fungal infections predominantly occur in immunocompromised patients and many are acquired in hospitals;

- Aspergillus genus should always be target in clinical environment and should be considered as a main IAQ concern. 


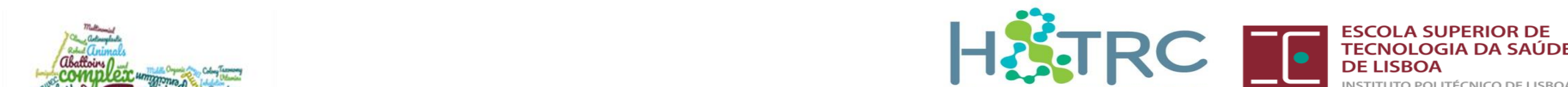

\section{Even if the $1 / 0$ ratio cut-off is in accordance with legislation}

Qualitative assessment from the fungal burden (fungal species/sections identification) should be performed

Since toxigenic species can be present 


\section{Other critical points from Portuguese legislation:}

- Assessment should not be restrictive to the listed fungal species, since not all fungal/species with toxigenic potential, and common in indoor environments from Portugal, are listed (Aspergillus sections Nigri, Aspergilli and Nidulantes were also isolated).

- Portuguese legislation only relies on active methods (air sampling) and this can narrow the exposure assessment. 


\section{Take home messages (with further results):}

- A multi-approach in the sampling methods (active and passive) and analyses applied should be the trend.

More refined risk characterization
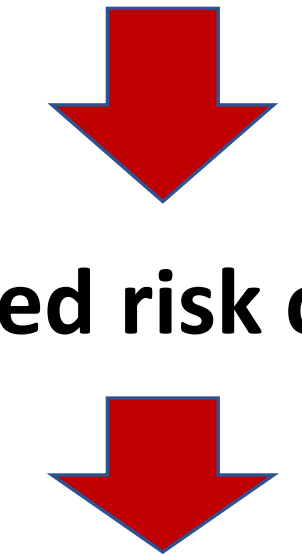

Suitable risk control measures to reduce patients and workers health outcomes. 


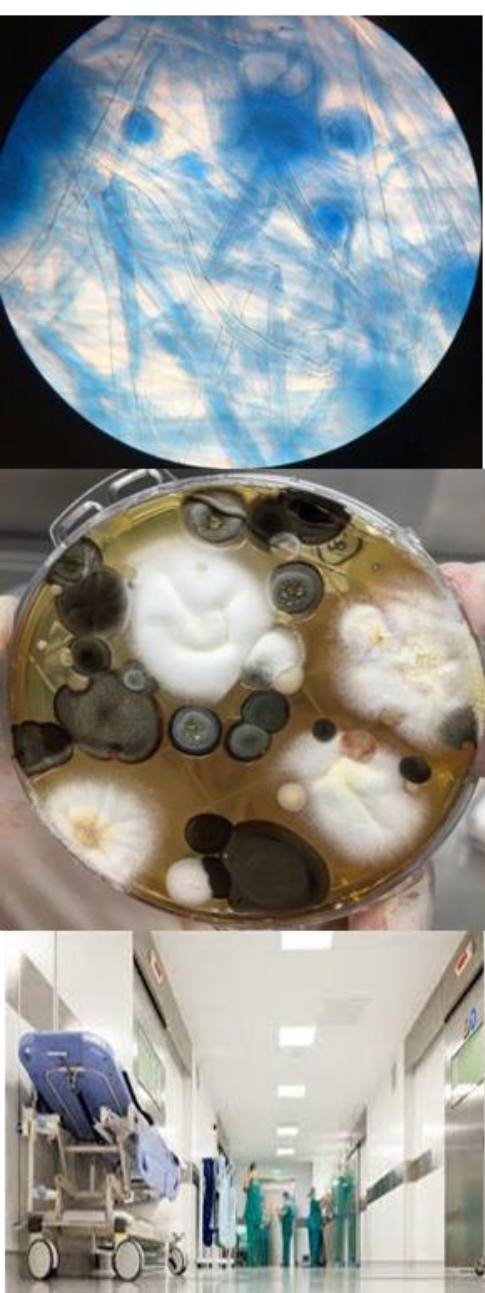

The quantitative cut-off applied to assess IAQ is not a suitable surrogate to ensure an IAQ regarding the mycobiota in health care facilities.

\section{Junho at ESTeSL - EXPOsE Seminar}

The author is grateful to FCT - Fundação para Ciência e Tecnologia for funding the project EXPOsE Establishing protocols to assess occupational exposure to microbiota in clinical settings (02/SAICT/2016

- Project no 23222).

\section{FCT: NORTE2020 Lisb@20 ${ }^{20}$}

